\title{
The insulin-like growth factor system and its receptors: A potential novel anticancer target
}

\author{
Colin R Lindsay' \\ $T$ R Jeffry Evans ${ }^{1,2}$ \\ 'Beatson West of Scotland Cancer \\ Centre, Glasgow, United Kingdom; \\ ${ }^{2}$ University of Glasgow, CR-UK \\ Beatson Laboratories, Garscube \\ Estate, Glasgow, United Kingdom
}

Correspondence: Colin R Lindsay Beatson West of Scotland Cancer Centre, 1053 Great Western Road, Glasgow

GI 2 OYN, United Kingdom

$\mathrm{Tel}+44$ I4I 30 I 7000

Fax +44 I4I $30 \mid 7284$

Email colin.lindsay@ggc.scot.nhs.uk

\begin{abstract}
The current generation of novel anticancer therapies that are in preclinical and clinical development are based on exploiting our increasing understanding of the molecular and cellular basis of cancer development and progression. Accelerated rates of cell division and proliferation have been postulated to predispose to the development of malignant disease. The insulin-like growth factor (IGF) signaling system has an important physiological role in regulating cellular proliferation and apoptosis. This function has led to considerable interest in its relevance to neoplasia over the last decade. In this review, we give an overview of the IGF system physiology, discuss the epidemiological significance of IGF signaling and neoplasia, and review the preclinical and clinical studies in targeting IGF receptors as cancer therapies.
\end{abstract}

Keywords: insulin, growth factor, IGF-1, clinical trials

\section{Insulin-like growth factor system physiology}

Childhood growth in both humans and mice has been closely linked to the insulin-like growth factor (IGF) system (Liu et al 1993; Pollak et al 2004). It is largely constituted by two ligands (IGFI and IGFII) which interact with two receptors, IGF receptors I and II (IGFIR and IGFIIR). The complexity of the network has been significantly underlined by the identification of at least 6 IGF-binding proteins (IGFBPs), for which the functional characteristics have yet to be fully defined (LeRoith et al 2003). The presence of hybrid receptors between IGFIR and the insulin receptor (IR) has also been described (Federici et al 1997). Several proteins downstream of IGFIR have been identified, including TOR, the insulin-receptor substrate (IRS) family, AKT, MAP kinase, and S6 kinase (Pollak et al 2004). The ultimate targets of these kinase cascades are members of the Ets and forkhead transcription factor families, the regulation of which provide a mechanism by which the IGF system can elicit changes in gene expression that eventually mediate their effects on cellular proliferation and apoptosis (LeRoith et al 1995).

IGFI is largely produced in the liver and the upregulation of IGFI gene expression is stimulated by growth hormone (GH). It is also synthesized in extrahepatic sites (Jones et al 1995). It acts (along with IGFII) as a ligand for IGFIR, a cell-surface tyrosine kinase signaling molecule, which is highly related to the IR. It is a potent mitogen for a wide variety of cells and exerts its action by increasing DNA synthesis and by stimulating the expression of cyclin $\mathrm{D}_{1}$, which accelerates the cell cycle from $\mathrm{G}_{1}$ to $\mathrm{S}$ phase (Furlanetto et al 1994; Dufourny et al 1997). It also inhibits apoptosis by stimulating expression of Bcl proteins and suppressing expression of Bax (Minshall et al 1997; Parrizas et al 1997). On activation by its ligands, IGFIR phosphorylates the downstream targets mentioned above (Pollak et al 2004). Physiological activation of IGFIR and its hybrid receptors by overexpression alone is not seen, and thus, unlike with the epidermal growth factor (EGF) receptor family, activation of IGFIR requires 
ligand-binding in most settings (Yee 2006). Consistent with this, apart from the endocrine response of IGFIR to plasma IGF1 levels, model systems have demonstrated autocrine production of ligands (Khandwala et al 2000). IGFIR also has very close homology to the IR, with their ATP-binding sites exhibiting 100\% sequence identity, and their entire kinase domains sharing 84\% sequence identity (Garcia-Echeverria et al 2004).

IGFII also has mitogenic and antiapoptotic actions which help regulate cell proliferation and differentiation. However it is believed to play a less important role in post-natal growth than IGFI, with animal experiments demonstrating that it exerts its influence during the early phases of growth and its role after birth is gradually replaced by IGFI (Yu and Rohan 2000). The IGFIIR appears to have no intracellular kinase domain and, unlike IGFIR, may not act as a signaling molecule, despite having a high affinity for IGFII (MacDonald et al 1988).

IGFBPs are yet to be well defined but seem to have the potential to influence both stimulation and inhibition of IGFIR signaling, depending on the physiological context (Firth and Baxter 2002). The IGFBPs themselves are regulated by proteolysis regulated by various proteases (Baxter 2000). It has been observed that IGFBPs (particularly IGFBP3) have the same affinity for IGFI as the IGFIR, leading to the suggestion that their inhibitory effect is mediated through binding to IGF1 and hence competitive inhibition of its effect on IGFIR. Alternatively, IGFBPs may promote IGFIR signaling by prolonging the IGF half-life through binding. Furthermore, the IGFBPs have also been found to have growth stimulatory actions independent of their binding to the IGF (Collett-Solberg and Cohen 1996; Kelley et al 1996).

In this review, we discuss the epidemiological studies that relate the IGF system to various types of malignant disease, and explore in more detail the in vitro, in vivo, and clinical studies with agents which target IGF receptors as cancer therapy.

\section{IGF and cancer: epidemiology studies}

There are a myriad of epidemiologic studies which have investigated the IGF system and its specific relationship with different cancer types. The results of such studies demonstrate that it is difficult to identify individuals at risk of specific cancers by analysis of serum levels of the IGF system alone. Moreover, plasma levels of IGFI cannot be assumed to reflect IGF signaling given the potential for both autocrine and paracrine activation of IGFIR. Most positive epidemiologic studies demonstrate a fairly modest increased risk of malignancy with high plasma IGFI levels. However chronic exposure to a modest risk factor may be more relevant to cancer development than infrequent exposure to a strong risk factor (Pollak et al 2004).

Prostate cancer is the malignancy that has been most studied in terms of an epidemiologic association with the IGF system. The results have been conflicting. However, the general consensus is that prospective case control studies have fairly consistently demonstrated a correlation between serum IGFI levels and prostate cancer risk. The strongest association applies to young men, with a four-fold increase in risk described for the highest compared to the lowest levels of IGFI in men under 59 years (Stattin et al 2004).

It has also been well documented that circulating IGFI levels are positively correlated with premenopausal (but not postmenopausal) breast cancer (Hankinson et al 1998). Other studies also have supported a positive correlation between breast cancer risk in general and IGFI levels (Peyrat et al 1993; Vadgama et al 1999), although no difference exists between cases and case controls in some studies (Favoni et al 1995). Nevertheless there does seem to be a positive association between circulating IGFI levels and mammographic density (Maskarinec et al 2003), which in itself is strongly associated with breast cancer risk (Boyd et al 2002). In colon cancer, conflicting results exist with regards to a potential association, but most studies suggested that both IGFI and IGFII plasma levels were positively correlated with cancer risk compared to controls (El Atiq et al 1994; Ma et al 1999; Palmqvist et al 2002).

\section{Risk factor studies}

Insulin and the IGF system constitute a common physiological basis for many well-defined malignancy risk factors described on an epidemiologic level, including raised body mass index (BMI), high calorie intake, higher birthweight, and lack of exercise.

The Million Women Study offers the most robust epidemiologic support for a strong association between BMI and cancer risk (Reeves et al 2007). A higher BMI was associated with a significant increase in the risk of cancer for 10 out of 17 specific cancer types examined. Among postmenopausal women in the UK, 5\% of all cancers were attributable to being overweight or obese. For endometrial cancer and adenocarcinoma of the oesophagus, BMI represented a major modifiable risk factor; about half of all cases in postmenopausal women are attributable to overweight or obesity. Obesity has also been implicated in 
causing up to a $20 \%$ increase in breast cancer risk in those with a BMI over 30 , with a $20 \%$ increase in risk of metastasis for women who have already been diagnosed with breast cancer (Freudenheim et al 1996).

Many studies have indicated that dietary control and reduced calorie intake may have a protective effect against cancer. Increased levels of IGFI have been associated with both high levels of energy intake and high dairy intake (Giovanucci et al 2003). Prostate cancer risk, in turn, has been associated with both increased IGFI levels and increased dairy intake, leading to speculation that we may in future be able to identify individuals at high risk who may benefit from dietary restriction (Chan et al 2001; Pollak 2001). It has also been shown that intake of vegetables appears to decrease premenopausal breast cancer risk, with no isolated dietary factor explaining this effect (Freudenheim et al 1996). It is of interest that protection against carcinogenesis has been demonstrated by starvation and subsequently reversed by infusion of IGFI, suggesting a mediating role for IGFI in the protective effect of diet on carcinogenesis (Dunn et al 1997).

IGFI is very strongly associated with prenatal growth in particular. There are suggestions that high birthweight is positively associated with the risk of developing various cancer types including colorectal and prostate (Tibblin et al 1995; Sandhu et al 2002). Two large prospective cohorts have also demonstrated that high birthweight is a risk factor for premenopausal breast cancer (Michels et al 2006). An individual's height has also been shown to contribute to a modest increase in cancer risk (Engeland et al 2003; Lawlor et al 2003), although it has not been shown to have an association with plasma IGFI levels (Landin-Wilhelmsen et al 1994).

Regular physical activity whilst healthy can lead to up to a $20 \%$ reduction in risk of breast cancer later in life (Bernstein et al 2005). Furthermore, exercise after a breast cancer diagnosis has been strongly linked to improved quality of life and mortality risk reduction of up to $6 \%$ in those who perform the most physical activity (Holmes et al 2005). There has however been no consistent demonstration that an association exists between IGFI levels and physical activity (Landin-Wilhelmsen et al 1994; Rudman and Mattson 1994).

\section{IGF system pathophysiology IGFI and IGFIR}

IGFIR activation has been shown to induce proliferation and metastasis of cancer cells in vitro. This occurs either as an endocrine response to high levels of circulating IGFI or in response to autocrine production by tumor cells (Khandwala et al 2000). Pollak and colleagues (2004) speculated that, although there is evidence that experimental IGFI-positive cancers respond to fluctuating levels of IGFI, some malignancies probably respond to IGFI or IGFII produced in an autocrine or paracrine manner. This hypothesis would be consistent with the observation that IGF1R mRNA expression was decreased in prostate cancer tissue compared with normal prostate tissue, suggesting a role for chronic stimulation by an autocrine loop (Tennant et al 1996). Such a variation in IGFIR activation would imply that the efficacy of any treatment methods aimed to inhibit IGFIR signaling would not be reflected by serum IGFI levels (Pollak et al 2004).

Several in vivo laboratory models of carcinogenesis have consolidated the purported relationship between the IGFI system and malignancy seen in epidemiologic research. Transgenic mice overexpressing human IGFI in basal epithelial prostate cells showed a $50 \%$ rate of prostate neoplasia by the age of 6 months (DiGiovanni et al 2000). In contrast, the incidence of prostate cancer is markedly reduced in IGFI-deficient mice (Majeed et al 2003). IGFI gene-deleted mice, which have $25 \%$ of the circulating IGFI observed in normal mice, have also been used to study breast cancer development. Following carcinogen exposure, approximately $30 \%$ of IGFI-deficient mice developed mammary tumors, compared to $60 \%$ of normal mice (Wu et al 2003). Transgenic mice that overexpress growth hormone $(\mathrm{GH})$ and consequently have higher circulating levels of IGFI, also develop mammary tumors at higher frequency (Tornell et at 1991). In contrast, hepatic carcinogenesis is attenuated in mice with diminished IGFIR signaling (Lu and Archer 2003).

In addition to involvement in carcinogenesis, it has also been proposed that IGFI has a significant role in the development of metastases. Overexpression of the IGFIR in certain malignancies has been shown to be associated with aggressive behavior (Xie et al 1999). Evidence consistent with this includes the discovery that IGFI can upregulate VEGF gene expression and stimulate angiogenesis in a breast cancer cell line (Oh et al 2002). IGFI stimulation has also been shown to activate motility and migration of melanoma and neuroblastoma cancer cell lines (Meyer et al 2001; Satyamoorthy et al 2002).

\section{IGFII and IGFIIR}

IGFII is also implicated in malignancy. It has similar mitogenic and antiapoptotic mechanisms to IGFI, thereby also contributing to cell proliferation. Loss of genomic imprinting in the IGFII gene is often seen in malignancy 
(Jarrard et al 1995; Oda et al 1997), and it is the gene most overexpressed in colorectal cancer cells (Zhang et al 1997). IGFII transgenic mice have a higher incidence of hepatocellular carcinoma and lymphoma, as well as several other tumors, compared to controls after 18 months of age (Rogler et al 1994). IGFII has also been observed to have higher levels of expression in cancer cells with a strong tendency to metastasize (Guerra et al 1996).

The IGFII receptor has no tyrosine kinase activity and therefore does not transduce any signals when binding to IGFII. It is therefore postulated to function as a tumor-suppressor (or 'sink'), exerting its influence through its affinity for IGFII which would otherwise activate the IGFIR (Oates et al 1998). Loss of IGFIIR has been demonstrated in cancer and is correlated with increased IGFIR activation (MacDonald et al 1998).

\section{Targeting the IGF system: preclinical development}

Three components of the IGF system have been identified as potential targets for inhibiting its mitogenic and antiapoptotic properties: IGFIR regulators and ligands, the IGFIR itself, and downstream signaling pathways such as AKT and TOR (Figure 1).

\section{IGFIR regulators and ligands}

One potential upstream target in the IGF pathway is GH. Disrupting its action with the use of therapeutics such as somatostatin analogues (for example, octreotide) or GH releasing hormone antagonists has shown both anticancer efficacy in preclinical models and a reduction in plasma IGFI levels (Pollak and Schally 1998; Letsch et al 2003). However, the results of clinical trials with these agents has been generally disappointing. This may be because GH has no effect on IGFII, which may be upregulated in response to diminished IGFI-induced IGFIR signaling. IGFII is not expressed in adult mice (DeChiara et al 1991), and it has therefore not yet been possible to model the approach of targeting the IGF system regulators and ligands in vivo accurately.

Agents generated to interfere directly with IGFI, IGFII, or the IGFBPs may represent an alternative mechanism for

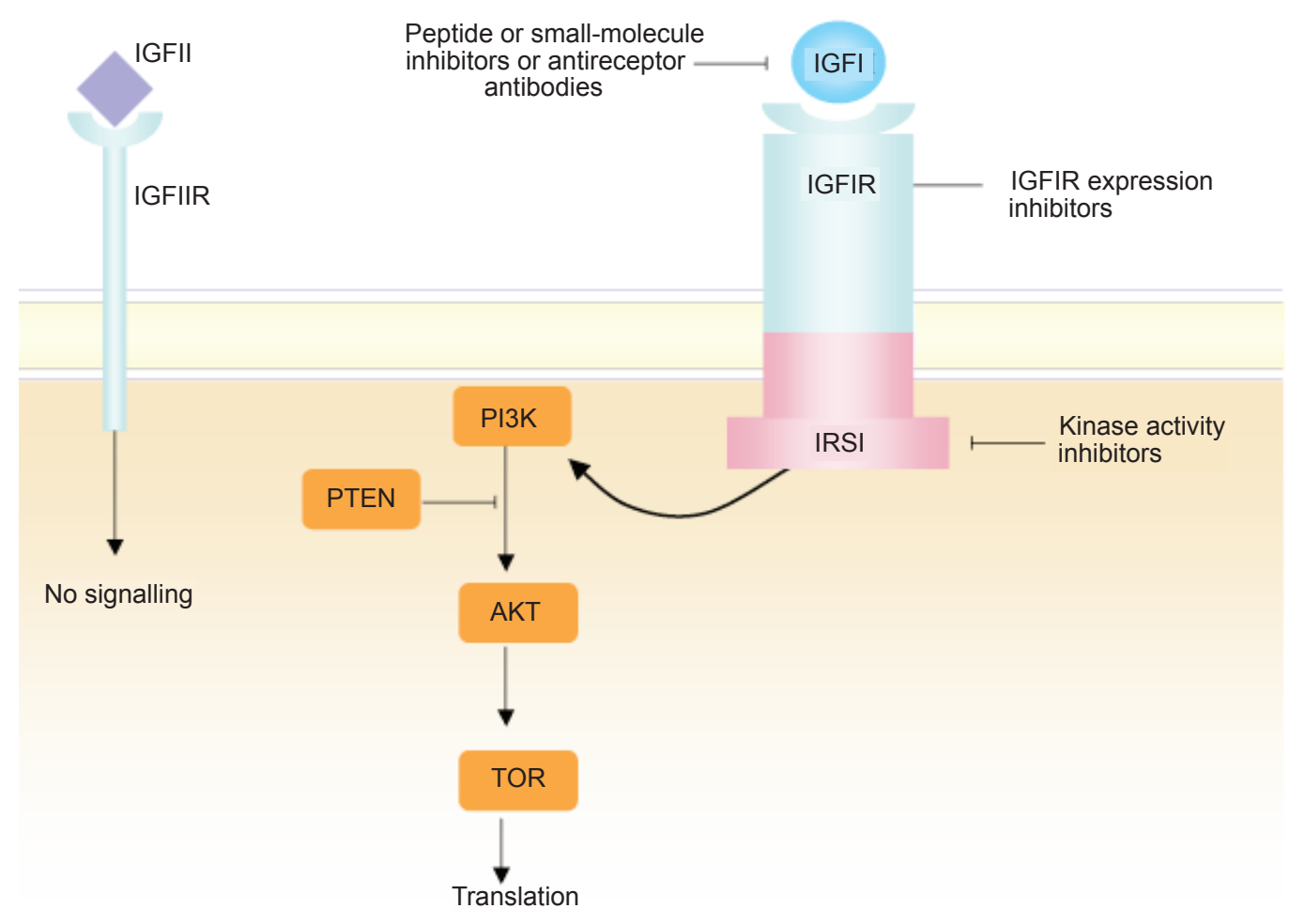

Figure I Overview of initial IGFIR and IGFIIR receptor activation and downstream signalling. Main opportunities for possible pharmacological intervention targeted towards IGFIR are also indicated. Pharmacological intervention against downstream signalling pathways such as AKT and TOC have been extensively reviewed elsewhere. IGFIIR has no kinase domain and appears to act as a sink, preventing IGFII binding and activation of IGFIR.

Abbreviations: IGFIR, Insulin growth factor receptor I; IGFIIR, Insulin growth factor receptor II; IGFI, insulin growth factor I; IGFII, insulin growth factor II; IRSI, insulin receptor substrate I;TOR, phosphoinositide-3-Kinase; PI3K, target-of-rapamycin. 
inducing anticancer activity. One recent exciting example of this possible therapeutic intervention involves curcumin, an agent with anticarcinogenic and chemo-preventive properties found in high levels in turmeric. This agent has shown an ability to down-regulate the IGFI axis in MCF-7 cell lines (Xia et al 2007). The purported mechanism for this effect is increased sequestration of IGF ligands by IGFBP3, rendering IGFI unavailable for binding to and activation of IGFIR. Moreover, curcumin in combination with 5FU/oxaliplatin chemotherapy in vitro produced greater inhibition of growth and stimulation of apoptosis in colon cancer cells compared to 5FU/oxaliplatin alone (Patel et al 2008).

\section{IGFIR}

Monoclonal antibodies currently constitute the majority of agents that have been developed to target IGFIR, and were the first agents that target IGF1R to enter clinical trials. Several antibodies directed against IGFIR have been developed and have shown a common anticancer mechanism of IGFIR down-regulation ( $\mathrm{Li}$ et al 2000; Burtrum et al 2003; Maloney et al 2003). CP-751,871 is a fully human IgG2 antibody with high affinity for human IGF-1R, which has now entered human clinical trials (see below). It has been shown in preclinical studies to block binding of IGF1 to IGFIR, IGFI-induced receptor autophosphorylation, and induce the downregulation of IGFIR in vitro and in tumor xenografts. It has also demonstrated significant antitumor activity both as a single agent and in combination with adriamycin, 5-fluorouracil, or tamoxifen in multiple tumor models (Cohen et al 2005). Sachdev and colleagues (2003) examined in vitro and in vivo mechanisms of the monoclonal antibody, scFv-Fc, on MCF-7 breast cancer cells, and proposed that it potentially downregulates the IGFIR via the endosomal endocytic pathway. It was also noted that, aside from blocking IGFIR activation, scFv-Fc appeared to have direct antitumor properties, possibly by altering the distribution of cell cycle components. Another fully human antibody that targets IGFIR, IMC-A12, has shown antitumor effects in a number of cancers in vivo (breast, renal, pancreatic, multiple myeloma) by inducing IGFIR internalization and degradation, resulting in a significant reduction in cell surface receptor density (Rowinsky et al 2007; Wu et al 2007).

Small molecule tyrosine kinase inhibitors of IGFIR have also been developed and recently entered human clinical trials. Potent antitumor effects of small molecule inhibitors have been demonstrated in preclinical studies for a variety of cancer types. Activity of the tyrosine kinase inhibitor, NVP-ADW742, has been demonstrated against multi-drug resistant multiple myeloma cell lines (Mitsiades et al 2004). In vivo, the orally bioavailable compound, NVP-AEW541, inhibited IGFIR signaling in tumor xenografts and significantly reduced the growth of IGFIR-driven fibrosarcomas (Garcia-Echeverria et al 2004). Another recent study utilized an alternative IGFIR kinase inhibitor, PQIP, for once daily oral administration, and showed robust antitumor efficacy in colorectal cancer xenografts which was correlated with the degree and duration of inhibition of tumor IGFIR phosphorylation by the compound (Ji et al 2007). Moreover, a novel class of IGFIR/IR receptor inhibitors have also shown potential clinical application with their antiproliferative and proapoptotic activity leading to significant inhibition of the growth in vivo (Haluska et al 2006). One potential concern regarding inhibition of IGF1R tyrosine kinase is the close homology of IGFIR to the IR, and the possibility of drug-induced hyperglycemia. However, early results in clinical trials have so far been favorable with regard to potential detrimental effects on glucose metabolism (see below).

The use of dominant-negative IGFIR is an alternative therapeutic strategy which is at an earlier stage of preclinical development, but has also shown promise. The development of metastases from breast cancer cells has been shown to be inhibited by a truncated dominant-negative IGFIR. By transfecting a dominant-negative form of IGFIR into metastatic breast cancer cell lines, Dunn and colleagues (1998) showed that metastases were significantly decreased, although this method did not significantly suppress primary tumor growth. These findings were supported by an in vivo study of colon cancer which showed decreased tumor growth, cell proliferation, and vascular endothelial growth factor (VEGF) expression in nude mice who were transfected with an alternative truncated dominant-negative form of IGFIR (Reinmuth et al 2002). Moreover, tumor formation and metastatic abilities were reduced and survival increased with the use of this method in vivo in Ewing's sarcoma cells (Scotlandi et al 2002).

Antisense RNA and gene disruption also constitute preclinical strategies with early success. Reduction in IGFIR expression, cancer cell growth, and proliferation have been shown in vivo with the use of this method (Sell et al 1994; Bohula et al 2003). Chernicky and colleagues (2000) also demonstrated in vivo efficacy of this method in mammary tumors: injection of IGFIR antisense RNA into nude mice led to both a delay in tumor formation and a dramatic reduction in tumor size. As with the studies examining dominant-negative IGFIR, the studies looking at antisense RNA as a therapeutic 
strategy have suggested that IGFIR particularly plays a role in progression and metastasis of cancer.

\section{Downstream targets}

Downstream proteins in the IGF system such as AKT, TOR, or MAP kinase represent alternative targets for inhibition of IGFIR signaling, and may not be associated with compensatory mechanisms for decreased IGFIR signaling which could exist further upstream. The rationale for such 'cross-talk' further upstream is validated by the observations that resistance to HER2 inhibition is associated with increased IGFIR signaling (Nahta et al 2005), and also that suppression of IGFIR signaling led to inhibition of non-small cell lung cancer proliferation by gefitinib (Morgillo et al 2007). A number of agents which target these downstream proteins are in preclinical and clinical development and have been extensively reviewed elsewhere.

\section{Targeting the IGF system: clinical development}

All the clinical trials that have been published to date have involved strategies aimed at blocking the IGFIR. Targeting IGFIR represents a conceptually different therapeutic approach compared to the rationale employed for the use of some other biological treatments, such as imatinib, which acts on single molecular targets that are unique or overexpressed in tumor cells compared to normal cells. Although the IGF system is expressed in a wide range of malignancies, it is also expressed ubiquitously in normal human tissue. Thus it is likely that agents which target IGFIR will have a therapeutic window with the optimal dose being that which inhibits IGFIR function that sustains tumor cell growth without compromising survival of normal cells. Currently there is relatively little clinical data arising from the large body of preclinical research in this area. Published literature (mostly abstracts) on clinical trials of IGFIR inhibitors have begun to emerge during recent years, and it is likely that mature clinical data will continue to emerge for these studies in the near future. Almost all of the published clinical information arises from early phase clinical trials. These trials utilize IGF1R inhibitors either as monotherapy or as part of combination therapy regimens. Clinical studies with somatostatin analogues, AkT, TOR, and MAP kinase inhibitors have been extensively reviewed elsewhere. In this section, we focus on the emerging clinical studies with IGFIR inhibitors.

\section{IGFIR inhibitors: Single agent studies}

Three phase I studies of monoclonal antibodies targeted against IGF1R have been published (Lacy et al 2006;
Haluska et al 2007; Higano et al 2007). CP-751,871 is a fully human $\mathrm{IgG}_{2}$ monoclonal antibody (mAb) antagonist of IGF-1R used in two of the studies (Lacy et al 2006; Haluska et al 2007). The other trial studied IMC-A12, a fully human $\mathrm{IgG}_{1} \mathrm{mAb}$ also directed against IGF-1R (Higano et al 2007).

\section{Toxicity analyses}

Safety and tolerability has to date been favorable with the use of these agents in phase I studies. One of the phase I studies of CP-751,871 did not define the maximum tolerated dose (MTD) of CP-751,871 as it exceeded the maximum feasible dose (MFD) of $20 \mathrm{mg} / \mathrm{kg}$ (Haluska et al 2007). There were no treatment-related toxicities greater than NCI-CTC grade 3 observed in this study. One grade 3 episode of fatigue and arthralgia occurred at the maximal dose administered. Grades I/II toxicities included hyperglycemia, anorexia, elevated AST/GGT, diarrhoea, hyperuricemia, and fatigue. Two patients received at least 16 three-weekly cycles without demonstrating evidence of cumulative toxicity, and patients were able to tolerate repeated cycles of CP-751,871 at doses several orders of magnitude above the minimal biologically effective concentration (Cohen et al 2005).

These toxicity findings were consistent with the observation from two other monotherapy studies of IGFIR antibodies (Lacy et al 2006; Higano et al 2007). No dose-limiting toxicities (DLTs) were reported in the phase I study of CP-751,871 in patients with advanced multiple myeloma (MM). One DLT (grade 3 hyperglycemia) was observed in the phase I study of IMC-A12, but otherwise toxicities were again limited to grade 1 (pruritis, rash, discolored feces) and grade 2 (anemia, psoriasis, hyperglycemia, infusion-related reaction) levels despite a more intensive weekly dosing regimen with this IGFIR inhibitor.

Prior to clinical evaluation, hyperglycemia was considered to be the likely drug-related toxicity in clinical trials, and certainly it is the most common laboratory related abnormality from current evidence (albeit nearly all at grade 1 or 2 level). However, at a preclinical level, it was anticipated that monoclonal antibodies were specific enough to avoid inhibition of the IR despite its extensive homology with IGFIR. Furthermore, Haluska and colleagues (2007) established that the $\mathrm{C}_{\max }$ with repeated dosing of $\mathrm{CP}-751,871$ in their trial was less than a third of what earlier investigation had shown to be the concentration necessary for binding to the IR (Cohen et al 2005; Haluska et al 2007). 
The above data has therefore led to an alternative hypothesis which does not attribute raised glucose levels to IR-binding by IGFIR inhibitors. Alternatively it has been suggested that IGFI has an important role in regulation of glucose homeostasis, whereby inhibition of its ligand action on IGFIR could lead to hyperglycemia. Data consistent with this theory includes the finding that IGFI administered to humans results in hypoglycemia (Guler et al 1987; Schmitz et al 1991), as well as the knowledge that recombinant IGFI has been shown to improve glucose control in type II diabetics by increasing insulin sensitivity (Moses et al 1996). This potential shift in conception of the causality of hyperglycemia could have significant implications in the long-term for use of monoclonal antibodies over small molecule tyrosine kinase inhibitors in the targeting of IGFIR, as the main purported advantage of immunological treatments is that they are more specific to the IGFIR. Small molecule inhibitors already have the advantage of being available as a convenient oral therapy. Furthermore, there is a body of preclinical evidence that suggests IR (as well as IGFIR) potentially has a role in carcinogenesis itself, thereby suggesting that CP-751,871 does not reach appropriate pharmacologic concentrations to achieve an optimal anticancer effect on human insulin receptors.

An interesting observation in the endocrine analysis of three-weekly administration of CP-751,871 is that insulin levels cumulatively increased in patients who received prolonged administration. This was therefore proposed as a potential compensatory mechanism for control of hyperglycemia caused by IGFI inactivation (Haluska et al 2007). Further endocrine studies are required in future clinical trials for further characterisation of all of the above findings.

\section{Clinical responses}

Although a secondary endpoint for phase I studies, encouraging clinical responses have been observed in preliminary data from studies of IGFIR inhibitors as single agents. Weekly administration of IMC-A12 induced stable disease in 2 of 11 patients for over 9 months at the time of reporting, with another three patients showing disease stability after their first 4-weekly cycle with dose escalation continuing (Higano et al 2007). Furthermore, there was 1 near complete response (CR) and 2 partial responses (PRs) seen in patients with MM treated with CP-751,871 in combination with dexamethasone (Lacy et al 2006). Haluska and colleagues (2007) reported that 7 of 12 patients with advanced solid tumors receiving CP-751,871 at $20 \mathrm{mg} / \mathrm{kg}$ had small reductions in measurable tumor size. Furthermore, two patients had prolonged disease stabilization for over 48 weeks. These findings are encouraging given the advanced refractory disease of patients who enter into early phase clinical trials.

\section{IGFIR inhibitors: combination therapy studies}

Synergy between biological treatments and chemotherapies is not necessarily easily predicted. Successes such as trastuzumab in combination with taxanes (Slamon et al 2001) are outweighed by other failed combination attempts (Herbst et al 2004). It has been suggested that IGFIR inhibitors may act in either way and this could be dependent on the strategy used: monoclonal antibody treatments are thought to potentially synergize with chemotherapy by lowering the apoptotic threshold of cancer cells, while it is speculated that tyrosine kinase inhibitors may interfere with the cell cycle specific effects of chemotherapy by blocking progression through to S-phase (Yee 2006).

Two trials involving IGFIR inhibitors in combination with chemotherapy have been reported. One phase I trial analyzed the combination of varying doses of CP-751,871 administered with docetaxel $\left(75 \mathrm{mg} / \mathrm{m}^{2}\right)$ at 3-weekly intervals in patients with advanced cancer (Attard et al 2006). Again the MTD had not been reached in this trial and toxicities experienced in patients were felt to be attributable to the chemotherapy. Only a transient grade 1 episode of hyperglycemia was noted, and this had occurred following steroid use prior to taxane administration. No cardiac toxicity was observed on serial echocardiograms. Response rates were again encouraging with 5 patients receiving CP-751,871 alone reported as having stable disease.

Phase II evidence has now begun to emerge with an interim analysis of paclitaxel and carboplatin with or without CP-751,871 in stage IIIb/IV NSCLC recently being reported (Karp et al 2007). Impressive response rates were observed in the 73 patients analysed, although more data with regard to toxicity emerged. The response rate was $46 \%$ in the IGFIR inhibitor group compared with $32 \%$ in the chemotherapy alone group, and it was noted in particular that $52 \%$ of the nonadenocarcinoma patients responded to treatment. Furthermore, a PR was observed in a patient who received single agent CP-751,871 following progression on chemotherapy alone. Hyperglycemia ( $20 \%$ vs $10 \%)$, fatigue ( $15 \%$ vs $8 \%$ ), and neuropathy ( $10 \%$ vs $4 \%$ ) were, however, found to be more prevalent in the IGFIR inhibitor group.

\section{Biological markers}

It is clear from this review that the IGF system has a role implicated in several cancer types including breast, prostate, 
multiple myeloma, and sarcoma. However it is likely that different subtypes of patients with each of these cancers (for example, premenopausal breast cancer) may respond to IGFIR blockade more than other subtypes. It is therefore of great importance to discover molecular markers that can predict a high probability of clinical benefit from such treatment. Studies performed of cells which are IGFIR activated and yet lack a phenotypic response would suggest that this may not be straightforward (Yee 2006). Furthermore, as already discussed, IGF-related tumors are not necessarily associated with overexpression of IGFIR (as is the case with HER2), and plasma levels of IGFI and IGFII do not reflect IGFIR activation given that autocrine and paracrine mechanisms are likely to be involved also.

The most interesting biomarker study reported so far details the detection of circulating tumor cells (CTCs) with CP-751,871 blockade of IGFIR (de Bono et al 2007). IGFIR expression is detectable by immunofluorescence on CTCs. CTCs were commonest in advanced hormone-refractory prostate cancer patients, with detectable IGFIR expression on the CTCs showing an association with higher frequency of PSA declines by over 50\%. However, it was not possible to establish a dose-effect relationship with only $33 \%$ of patients having detectable CTCs at initiation of treatment. This lack of sensitivity represents the main limitation of this technique as a biomarker, and therefore its current use appears to be most promising in patients with large tumor burdens.

\section{Future developments}

Several phase II trials involving IGFIR inhibitors are now underway, the results of which are eagerly anticipated. Prostate cancer has been an area of particular interest. However, continuing research is also focused on trying to identify cancers at a biological level which might be susceptible to IGFIR antibody therapy, with the further characterization and early clinical trial use of appropriate biomarkers of particular importance.

\section{Disclosure}

The authors report no conflicts of interest in this work.

\section{References}

Attard G, Fong PC, Molife R, et al. 2006. Phase I trial involving the pharmacodynamic (PD) study of circulating tumor cells, of CP-751,871 (C), a monoclonal antibody against the insulin-like growth factor 1 receptor (IGF-1R), with docetaxel (D) in patients with advanced cancer. ASCO Annual Meeting Proceedings part I [abstract]. J Clin Oncol, 24(18S):3023.

Baxter RC. 2000. Insulin-like growth factor (IGF)-binding proteins: interactions with IGFs and intrinsic bioactivities. Physiol Endocrinol Metab, 278:E967-E976.
Bernstein L, Patel AV, Ursin G, et al. 2005. Lifetime recreational exercise activity and breast cancer risk among black women and white women. J Natl Cancer Institute, 97:1671-9.

Bohula EA, Salisbury AJ, Sohail M, et al. 2003. The efficacy of small interfering RNAs targeted to the type 1 insulin-like growth factor receptor (IGF1R) is influenced by secondary structure in the IGF1R transcript. J Biol Chem, 278:15991-7.

Boyd NF, Stone J, Martin LJ, et al. 2002. The association of breast mitogens with mammographic densities. Br J Cancer, 87:876-82.

Burtrum D, Zhu Z, Lu D, et al. 2003. A fully human monoclonal antibody to the insulin-like growth factor I receptor blocks ligand-dependent signaling and inhibits human tumor growth in vivo. Cancer Res, 63:8912-21.

Chan JM, Stampfer MJ, Ma J, et al. 2001. Dairy products, calcium, and prostate cancer risk in the Physicians' Health Study. Am J Clin Nutr, 74:549-54.

Chernicky CL, Yi L, Tan H, et al. 2000. Treatment of human breast cancer cells with antisense RNA to the type I insulin-like growth factor receptor inhibits cell growth, suppresses tumorigenesis, alters the metastatic potential, and prolongs survival in vivo. Cancer Gene Ther, 7:384-95.

Cohen BD, Baker DA, Soderstrom C, et al. 2005. Combination therapy enhances the inhibition of tumor growth with the fully human anti-type 1 insulin-like growth factor receptor monoclonal antibody CP-751,871. Clin Cancer Res, 11:2063-73.

Collett-Solberg PF, Cohen P. 1996. The role of the insulin-like growth factor binding proteins and the IGFBP proteases in modulating IGF action. Endocrinol Metab Clin North Am, 25:591-614.

De Bono JS, Attard G, Adjei A, et al. 2007. Potential applications for circulating tumor cells expressing the insulin-like growth factor-I receptor. Clin Cancer Res, 13:3611-6.

DeChiara TM, Robertson EJ, Efstratiadis A. 1991. Parental imprinting of the mouse insulin-like growth factor II gene. Cell, 64:849-59.

DiGiovanni J, Kiguchi K, Frijhoff A, et al. 2000. Deregulated expression of insulin-like growth factor 1 in prostate epithelium leads to neoplasia in transgenic mice. Proc Natl Acad Sci U S A, 97:3455-60.

Dufourny B, Alblas J, van Teeffelen HA, et al. 1997. Mitogenic signalling of insulin-like growth factor I in MCF-7 human breast cancer cells requires phosphatidylinositol 3-kinase and is independent of mitogen-activated protein kinase. $J$ Biol Chem, 272:31163-71.

Dunn SE, Kari FW, French J, et al. 1997. Dietary restriction reduces insulin-like growth factor I levels, which modulates apoptosis, cell proliferation, and tumor progression in p53-deficient mice. Cancer Res, $57: 4667-72$

Dunn SE, Ehrlich M, Sharp NJ, et al. 1998. A dominant negative mutant of the insulin-like growth factor-I receptor inhibits the adhesion, invasion, and metastasis of breast cancer. Cancer Res, 58:3353-61.

El Atiq F, Garrouste F, Remacle-Bonnet M, et al. 1994. Alterations in serum levels of insulin-like growth factors and insulin-like growth-factor-binding proteins in patients with colorectal cancer. Int J Cancer, 57:491-7.

Engeland A, Tretli S, Bjorge T. 2003. Height, body mass index, and prostate cancer: a follow-up of 950000 Norwegian men. Br J Cancer, 89:1237-42.

Favoni RE, de Cupis A, Perrotta A, et al. 1995. Insulin-like growth factor-I (IGF-I) and IGF-binding proteins blood serum levels in women with early- and late-stage breast cancer: mutual relationship and possible correlations with patients' hormonal status. J Cancer Res Clin Oncol, 121:674-82.

Federici M, Porzio O, Zucaro L, et al. 1997. Distribution of insulin/insulin-like growth factor-1 hybrid receptors in human tissues. Mol Cell Endocrinol, 129:121-6.

Firth SM, Baxter RC. 2002. Cellular actions of the insulin-like growth factor binding proteins. Endocr Rev, 23:824-54.

Freudenheim JL, Marshall JR, Vena JE, et al. 1996. Premenopausal breast cancer risk and intake of vegetables, fruits, and related nutrients. $J$ Natl Cancer Institute, 88:340-8. 
Furlanetto RW, Harwell SE, Frick K. 1994. Insulin-like growth factor I induces cyclin D1 expression MG63 human osteosarcoma cells in vitro. Mol Endocrinol, 8:510-7.

Garcia-Echeverria C, Pearson MA, Marti A, et al. 2004. In vivo antitumor activity of NVP-AEW541 - A novel, potent, and selective inhibitor of the IGF-IR kinase. Cancer Cell, 5:231-9.

Giovanucci E, Pollak M, Liu Y, et al. 2003. Nutritional predictors of insulin-like growth factor I and their relationships to cancer in men. Cancer Epidemiol Biomarkers Prev, 12:84-9.

Guerra FK, Eijan AM, Puricelli L, et al. 1996. Varying patterns of expression of insulin-like growth factors I and II and their receptors in murine mammary adenocarcinomas of different metastasizing ability. Int $J$ Cancer, 65:812-20.

Guler HP, Zapf J, Froesch ER. 1987. Short-term metabolic effects of recombinant human insulin-like growth factor $I$ in healthy adults. N Engl J Med, 317:137-40.

Haluska P, Carboni JM, Loegering DA, et al. 2006. In vitro and in vivo antitumor effects of the dual insulin-like growth factor-I/insulin receptor inhibitor, BMS-554417. Cancer Res, 66:362-71.

Haluska P, Shaw HM, Batzel GN, et al. 2007. Phase I dose escalation study of the anti insulin-like growth factor-I receptor monoclonal antibody CP-751,871 in patients with refractory solid tumors. Clin Cancer Res, 13:5834-40

Hankinson L, Strohm O, Osterziel K, et al. 1998. Insulin-like growth factor-I and risk of breast cancer. Lancet, 352:489-99.

Herbst RS, Giaccone G, Schiller JH, et al. 2004. Gefitinib in combination with paclitaxel and carboplatin in advanced non-small-cell lung cancer: a phase III trial - INTACT 2. J Clin Oncol, 22:785-94.

Higano CS, Yu EY, Whiting MS, et al. 2007. A Phase I, first in man study of weekly IMC-A12, a fully human insulin like growth factor-I receptor IgG1 monoclonal antibody, in patients with advanced solid tumors [abstract]. ASCO Prostate Cancer Symposium, 269.

Holmes MD, Chen WY, Feskanich D, et al. 2005. Physical activity and survival after breast cancer diagnosis. JAMA, 293:2479-86.

Jarrard DF, Bussemakers MJ, Bova GS, et al. 1995. Regional loss of imprinting of the insulin-like growth factor II gene occurs in human prostate tissues. Clin Cancer Res, 1:1471-8.

Ji QS, Mulvihil MJ, Rosenfeld-Franklin M, et al. 2007. A novel, potent, and selective insulin-like growth factor-I receptor kinase inhibitor blocks insulin-like growth factor-I receptor signaling in vitro and inhibits insulin-like growth factor-I receptor dependent tumor growth in vivo. Mol Cancer Ther, 6:2158-67.

Jones JI, Clemmons DR. 1995. Insulin-like growth factora and their binding proteins: iological actions. Endocr Rev, 16:3-34.

Karp DD, Paz-Ares LG, Blakely LJ, et al. 2007. Efficacy of the anti-insulin like growth factor I receptor (IGF-IR) antibody CP-751,871 in combination with paclitaxel and carboplatin as first-line treatment for advanced non-small cell lung cancer (NSCLC). ASCO Annual Meeting Proceedings part I [abstract]. J Clin Oncol, 25(18S):7506.

Kelley KM, Oh Y, Gargosky SE, et al. 1996. Insulin-like growth factor-binding proteins (IGFBPs) and their regulatory dynamics. Int J Biochem Cell Biol, 28:619-37.

Khandwala HM, McCutcheon IE, Flyvbjerg A, et al. 2000. The effects of insulin-like growth factors on tumorigenesis and neoplastic growth Endocr Rev, 21:215-44.

Lacy M, Alsina M, Melvin CL, et al. 2006. Phase I first-in-human dose escalation study of CP-751,871, a specific monoclonal antibody against the insulin like growth factor 1 receptor. ASCO Annual Meeting Proceedings part I [abstract]. J Clin Oncol, 24(18S):7609.

Landin-Wilhelmsen K, Wilhelmsen L, Lapps G, et al. 1994. Serum insulin-like growth factor $\mathrm{I}$ in a random population sample of men and women: relation to age, sex, smoking habits, coffee consumption and physical activity, blood pressure and concentrations of plasma lipids, fibrinogen, parathyroid hormone and osteocalcin. Clin Endocrinol, 41:351-7.

Lawlor DA, Okasha M, Gunnell D, et al. 2003. Associations of adult measures of childhood growth with breast cancer: findings from the British Women's Heart and Health Study. Br J Cancer, 89:81-7.
LeRoith D, Werner H, Beitner-Johnson D, et al. 1995. Molecular and cellular aspects of the insulin-like growth factor I receptor. Endocr Rev, 16:143-63.

LeRoith D, Roberts Jr. CT. 2003. The insulin-like growth factor system and cancer. Cancer Lett, 195:127-37.

Letsch M, Schally AV, Busto R, et al. 2003. Growth hormonereleasing hormone $(\mathrm{GHRH})$ antagonists inhibit the proliferation of androgen-dependent and -independent prostate cancers. Proc Natl Acad Sci U S A, 100:1250-5.

Li SL, Liang SJ, Guo N, et al. 2000. Single-chain antibodies against human insulin-like growth factor I receptor: expression, purification, and effect on tumor growth. Cancer Immunol Immunother, 49:243-52.

Liu JP, Baker J, Perkins AS, et al. 1993. Mice carrying null mutations of the genes encoding insulin-like growth factor I (IGFI) and type I IGF receptor (IGFIr). Cell, 75:59-72.

Lu S, Archer MC. 2003. Insulin-like growth factor binding protein-1 over-expression in transgenic mice inhibits hepatic preneoplasia. Mol Carcinogen, 36:142-6.

Ma J, Pollak M, Giovannucci E, et al. 1999. Prospective study of colorectal cancer risk in men and plasma levels of insulin-like growth factor (IGF)-I and IGF-binding protein-3. J Natl Cancer Inst, 91:628-9.

Macdonald RG, Pfeffer SR, Coussens L, et al. 1988. A single receptor binds both insulin-like growth factor II and mannose-6-phosphate. Science, 239:1134-7.

Majeed N, Kaplan P, Blouin M, et al. 2003. Lit is the first germ-line mutation to reduce prostate cancer risk and prolong survival in the TRAMP transgenic model. Proc Am Assoc Cancer Res, 44:877.

Maloney EK, McLaughlin JL, Dagdigian NE, et al. 2003. An anti-insulin-like growth factor I receptor antibody that is a potent inhibitor of cancer cell proliferation. Cancer Res, 63:5073-83.

Maskarinec G, William AE, Kaaks R. 2003. A cross-sectional investigation of breast density and insulin-like growth factor I. Int $J$ Cancer, 107:996.

Meyer GE, Shelden E, Kim B, et al. 2001. Insulin-like growth factor I stimulates motility in human neuroblastoma cells. Oncogene, 20:7542-50

Michels KB, Xue F, Terry KL, et al. 2006. Longitudinal study of birthweight and the incidence of breast cancer in adulthood. Carcinogenesis, 27:2464-8.

Minshall C. Arkins S, Straza J, et al. 1997. IL-4 and insulin-like growth factor I inhibit the decline in Bcl-2 and promote the survival of IL-3 deprived myeloid progenitors. J Immunol, 159:1225-32.

Mitsiades CS, Mitsiades NS, McMullan CJ, et al. 2004. Inhibition of the insulin-like growth factor receptor-1 tyrosine kinase activity as a therapeutic strategy for multiple myeloma, other hematologic malignancies, and solid tumors. Cancer Cell, 5:221-30.

Morgillo F, Kim WY, Kim ES, et al. 2007. Implication of the insulin-like growth factor-IR pathway in the resistance of non-small cell lung cancer cells to treatment with gefitinib. Clin Cancer Res, 13:2795-803

Moses AC, Young SC, Morrow LA, et al. 1996. Recombinant human insulin-like growth factor I increases insulin sensitivity and improves glycemic control in type II diabetes. Diabetes, 45:91-100.

Nahta R, Yuan LX, Zhang B, et al. 2005. Insulin-like growth factor-I receptor/human epidermal growth factor receptor 2 heterodimerization contributes to trastuzumab resistance of breast cancer cells. Cancer Res, 65:11118-28.

Oates AJ, Schumaker LM, Jenkins SB, et al. 1998. The mannose 6-phosphate/ insulin-like growth factor 2 receptor (M6P/IGF2R), a putative breast tumor suppressor gene. Breast Cancer Res Treat, 47:269-81.

Oda H, Shimizu S, Minami K, et al. 1997. Loss of imprinting of the IGF2 gene in a Wilms' tumor in an adult. $J$ Natl Cancer Institute, 89:1813-4.

Oh JS, Kucab JE, Bushel PR, et al. 2002. Insulin-like growth factor-1 inscribes a gene expression profile for angiogenic factors and cancer progression in breast epithelial cells. Neoplasia, 4:204-17. 
Palmqvist R, Hallmans G, Rinaldi S, et al. 2002. Plasma insulin-like growth factor 1, insulin-like growth factor binding protein 3, and risk of colorectal cancer: a prospective study in northern Sweden. Gut, 50:642-6.

Parrizas M, LeRoith D. 1997. Insulin-like growth factor I inhibition of apoptosis is associated with increased expression of the bcl-xL gene product. Endocrinology, 138:1355-8.

Patel BB, Sengupta R, Qazi S, et al. Curcumin enhances the effects of 5-fluorouracil and oxaliplatin in mediating growth inhibition of colon cancer cells by modulating EGFR and IGF-1R. Int J Cancer, 122:267-73.

Peyrat JP, Bonneterre J, Hecquet B, et al. 1993. Plasma insulin-like growth factor-I (IGFI) concentrations in himan breast cancer. Eur J Cancer, 29A:492-7.

Pollak M. 2001. Insulin-like growth factors and prostate cancer. Epidemiol Rev, 23:59-66.

Pollak MN, Schally AV. 1998. Mechanisms of antineoplastic action of somatostatin analogs. Proc Soc Exp Med Biol, 217:143-52.

Pollak MN, Schernhammer ES, Hankinson SE. 2004. Insulin-like growth factors and neoplasia. Nat Rev Cancer, 4:505-18.

Reeves GK, Pirie K, Beral V, et al. 2007. Cancer incidence and mortality in relation to body mass index in the Million Women Study: cohort study. BMJ, 335:1134.

Reinmuth N, Liu W, Fan F, et al. 2002. Blockade of insulin-like growth factor I receptor function inhibits growth and angiogenesis of colon cancer. Clin Cancer Res, 8:3259-69.

Rogler CE, Yang D, Rossetti L, et al. 1994. Altered body composition and increased frequency of diverse malignancies in insulin-like growth factor-II transgenic mice. J Biol Chem, 269:13779-84.

Rowinsky EK, Youssoufian H, Tonra JR, et al. 2007. IMC-A12, a human IgG1 monoclonal antibod to the insulin-like growth factor I receptor. Clin Cancer Res 13(18 Pt 2):5549s-5555s.

Rudman D, Mattson DE. 1994. Serum insulin-like growth factor I in healthy older men in relation to physical activity. $J$ Am Geriatr Soc, 42:71-6.

Sachdev D, Li SL, Hartell JS, et al. 2003. A chimeric humanized single-chain antibody against the type I insulin-like growth factor (IGF) receptor renders breast cancer cells refractory to the mitogenic effects of IGF-I. Cancer Res, 63:627-35.

Sandhu MS, Luben R, Day NE, et al. 2002. Self-reported birth weight and subsequent risk of colorectal cancer. Cancer Epidemiol Biomarkers Prev, 11:935-8.

Satyamoorthy K, Li G, Vaidya B, et al. 2002. Insulin-like growth factor-I-induced migration of melanoma cells is mediated by interleukin-8 induction. Cell Growth Differ, 13:87-93.

Schmitz F, Hartmann H, Stumpel F, et al. 1991. In vivo metabolic action of insulin-like growth factor I in adult rats. Diabetologia, 34:144-9.
Scotlandi K, Avnet S, Benini S, et al. 2002. Expression of an IGF-I receptor dominant negative mutant induces apoptosis, inhibits tumorigenesis and enhances chemosensitivity in Ewing's sarcoma cells. Int J Cancer, 101:11-6.

Sell C, Dumenil G, Deveaud C, et al. 1994. Effect of a null mutation of the insulin-like growth factor I receptor gene on growth and transformation of mouse embryo fibroblasts. Mol Cell Biol, 14:3604-12.

Slamon DJ, Leyland-Jones B, Shak S, et al. 2001. Use of chemotherapy plus a monoclonal antibody against HER2 for metastatic breast cancer that overexpresses HER2. N Engl J Med, 344:783-92.

Stattin P, Rinaldi S, Biessy C, et al. 2004. High levels of circulating insulin-like growth factor-I increase prostate cancer risk: a prospective study in a population-based non-screened cohort. J Clin Oncol, 22:3104-12.

Tennant MK, Thrasher JB, Twomey PA, et al. 1996. Protein and messenger ribonucleic acid (mRNA) for the type 1 insulin-like growth factor (IGF) receptor is decreased and IGF-II mRNA is increased in human prostate carcinoma compared to benign prostate epithelium. J Clin Endocrinol Metab, 81:3774-82.

Tibblin G, Eriksson M, Cnattingius S, et al. 1995. High birthweight as a predictor of prostate cancer risk. Epidemiology, 6:423-4.

Tornell J, Rymo L, Isakkson OG. 1991. Induction of mammary adenocarcinomas in metallothionein promoter-human growth hormone transgenic mice. Int J Cancer, 49:114-7.

Vadgama JV, Wu Y, Datta G, et al. 1999. Plasma insulin-like growth factor-I and serum IGF-binding protein 3 can be associated with the progression of breast cancer, and predict the risk of recurrence and the probability of survival in African-American and Hispanic women. Oncology, 57:330-40

Wu KD, Zhou L, Burtrum D, et al. 2007. Antibody targeting of the insulin-like growth factor I receptor enhances the anti-tumor response of multiple myeloma to chemotherapy through inhibition of tumor proliferation and angiogenesis. Cancer Immunol Immunother, 56:343-57.

Wu Y, Cui K, Miyoshi K, et al. 2003. Reduced circulating insulin-like growth factor I levels delay the onset of chemically and genetically induced mammary tumors. Cancer Res, 63:4384-8.

Xia Y, Jin L, Zhang B, et al. The potentiation of curcumin on insulin-like growth factor-1 action in MCF-7 human breast carcinoma cells. Life Sci, 80:2161-9.

Xie Y, Skytting B, Nilsson G, et al. 1999. Expression of insulin-like growth factor-1 receptor in synovial sarcoma: association with an aggressive phenotype. Cancer Res, 59:3588-91.

Yee D. 2006. Targeting insulin-like growth factor pathways. Br J Cancer, 94:465-8.

Yu H, Rohan T. 2000. Role of the insulin-like growth factor family in cancer development and progression. J Natl Cancer Inst, 92:1472-89.

Zhang L, Zhou W, Velculescu VE, et al. 1997. Gene expression profiles in normal and cancer cells. Science, 276:1268-72. 